\title{
Examination of the Change of the Characteristic X-Rays of the Zinc in Fluorine- and Boron-Doped ZnO Thin Films
}

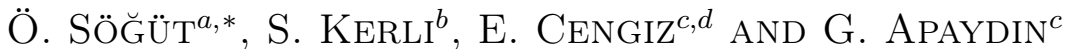 \\ ${ }^{a}$ Kahramanmaraş Sutcu Imam University, Faculty of Science and Letters, Department of Physics, \\ 46100 Kahramanmaraş, Turkey \\ ${ }^{b}$ Kahramanmaras Sutcu Imam University, Elbistan Technology Faculty Energy Systems Engineering, \\ 46300 Kahramanmaraş, Turkey \\ ${ }^{c}$ Karadeniz Technical University, Faculty of Science, Department of Physics, \\ 61080 Trabzon, Turkey \\ ${ }^{d}$ Alanya Alaaddin Keykubat Üniversitesi, Faculty of Engineering, Department of Fundamental Sciences, \\ 07450 Antalya, Turkey \\ (Received August 31, 2016; revised version July 28, 2017; in final form March 5, 2018) \\ In this study, $K_{\beta} / K_{\alpha}$ X-ray intensity ratios of zinc in pure zinc, undoped $\mathrm{ZnO}$ thin film and boron and \\ fluorine-doped $\mathrm{ZnO}$ thin films have been investigated. These samples have been excited by $59.5 \mathrm{keV} \gamma-\mathrm{rays}$ from \\ a ${ }^{241} \mathrm{Am}$ annular radioactive source. $K$ X-rays emitted by the samples have been counted using an Ultra-LEGe \\ detector with a resolution of $150 \mathrm{eV}$ at $5.9 \mathrm{keV}$. The $K_{\beta} / K_{\alpha}$ X-ray intensity ratios of the doped ZnO thin films \\ have been compared with that of the undoped $\mathrm{ZnO}$ thin film. The deviations between the results can be explained \\ by delocalization and/or charge transfer phenomena causing change in valence electronic configuration of zinc.
}

DOI: 10.12693/APhysPolA.133.1124

PACS/topics: 32.30.Rj, 78.70.En, 32.30.-r, 32.80.Fb

\section{Introduction}

Recently, thin film science has grown worldwide into a major research area. The importance of the coatings and the synthesis of new materials for industry have resulted in a tremendous increase of innovative thin film processing technologies [1-3]. $\mathrm{ZnO}$ is an $n$-type wide band gap semiconductor with a wide direct band gap of $3.37 \mathrm{eV}$ at room temperature and large exciton binding energy of $60 \mathrm{meV}$ [4]. $\mathrm{ZnO}$ thin films are materials widely used in numerous applications such as piezoelectric transducers, optical waveguides acousto-optic media, surface acoustic wave devices, conductive gas sensors, transparent conductive electrodes, solar cell windows, and varistors [59]. Many researchers have added dopant such as Li, B, $\mathrm{N}, \mathrm{F}, \mathrm{P}, \mathrm{Mg}, \mathrm{Co}, \mathrm{Cu}, \mathrm{Ge}, \mathrm{In}, \mathrm{Te}$, and $\mathrm{Zr}$ to the $\mathrm{ZnO}$ thin films for improving or changing the film's hardness, conductivity and optical, electronic, and electrical properties $[5,8,10-13]$.

Energy dispersive X-ray fluorescence (EDXRF) method and $K$ shell fluorescence parameters such as $\mathrm{X}$-ray intensity ratios, fluorescence yields, cross-sections, and vacancy transitions can be used to provide useful information on the electronic structure of $\mathrm{Zn}$ transition metal in the doped and undoped $\mathrm{ZnO}$ thin films. It is well known that the X-ray fluorescence parameters depend on the physical and chemical environments of the

*corresponding author; e-mail: omersogut@gmail.com elements in a sample. This dependence can be explained as due to changes of the $3 d$-electron population in the transition metal.

When looked at the literature, there are a lot of investigations on the characteristic X-ray parameters of the thin film alloys or thin films. The $K_{\beta} / K_{\alpha}$ intensity ratios of $\mathrm{Ti}, \mathrm{Cr}$ and $\mathrm{Ni}$ in $\mathrm{Cr}_{x} \mathrm{Ni}_{1-x}$ and $\mathrm{Ti}_{x} \mathrm{Ni}_{1-x}$ were measured by Bhuinya and Padhi [14]. They explained the results according to the charge transfer. Sögüt et al. [15] investigated the alloying effects on $K_{\beta} / K_{\alpha}$ intensity ratios in $\mathrm{Cr}_{x} \mathrm{Ni}_{1-x}$ and $\mathrm{Cr}_{x} \mathrm{Al}_{1-x}$ alloys and they reported that $K \mathrm{X}$-ray intensity ratios vary depending on the concentrations of elements in the alloys. Raj et al. [16] determined the valence electronic structure of $\mathrm{Fe}$ and $\mathrm{Ni}$ in $\mathrm{Fe}_{x} \mathrm{Ni}_{1-x}$ using relative $K \mathrm{X}$-ray intensity ratios. They observed changes in $3 d$-electron population of $\mathrm{Fe}$ and $\mathrm{Ni}$ for certain alloy compositions. Pawlowski et al. [17] determined the $K_{\beta} / K_{\alpha}$ intensity ratios of $\mathrm{Ti}$, $\mathrm{Cr}, \mathrm{Fe}$ and $\mathrm{Co}$ in some alloys. They report that the observed changes in the valence structure are due to the rearrangement of electrons between $3 d$ and $(4 s, 4 p)$ states of individual metal atoms. Furthermore, the investigations from $K$ to $L$ shell/subshells vacancy transitions of $\mathrm{Zn}$ and $\mathrm{Fe}$ in $\mathrm{Fe}_{x} \mathrm{Zn}_{1-x}$ thin film alloys were done by Söğüt [18]. Dogan et al. [19] measured the $K$ shell production cross-sections and $K_{\beta} / K_{\alpha}$ intensity ratios of $\mathrm{Cr}$ and $\mathrm{Zn}$ in different alloy compositions. They also calculated empirical and semi-empirical $K$-shell fluorescence yields and $K_{\beta} / K_{\alpha}$ intensity ratios. Cengiz et al. [20] investigated the $K$ shell fluorescence parameters of porous Ni-49 at.\% Ti shape memory alloys using EDXRF technique. The structure analyses of the alloys were made 
using X-ray diffraction (XRD) and X-ray photoelectron spectroscopy (XPS). They attributed the deviations between the experimental results and theoretical values of pure $\mathrm{Ti}$ and Ni to charge transfer phenomena and/or rearrangement of valence shell electrons and porosity.

The aim of this study is to investigate the variation of $K_{\beta} / K_{\alpha}$ X-ray intensity ratios of zinc in boron and fluorine doped $\mathrm{ZnO}$ thin films by using XRF technique according to the doping amount of boron and fluorine. The obtained values were compared with the value of undoped $\mathrm{ZnO}$ thin film.

\section{Experimental details}

\subsection{Sample preparation}

$\mathrm{ZnO}$ thin films were fabricated on glass substrates by using the airbrush spraying. The deposition of films was carried out in ambient air and under a fume hood. The base $\mathrm{ZnO}$ solution was prepared by dissolving $0.1 \mathrm{M}$ zinc chloride $\left(\mathrm{ZnCl}_{2}\right)$ in distilled water. For doping, $0.1 \mathrm{M}$ of boric acid $\left(\mathrm{H}_{3} \mathrm{BO}_{3}\right)$ and a $0.1 \mathrm{M}$ of ammonium fluoride $\left(\mathrm{NH}_{4} \mathrm{~F}\right)$ are dissolved in distilled water and they were added to the base solution in appropriate atomic ratio. The atomic ratios of $\mathrm{F} /(\mathrm{Zn}+\mathrm{B})$ in the solution are adjusted by changing $\mathrm{F}(1,2,3,4$, and 5 at.\%) and $\mathrm{B}(2,3,4$, and 5 at. $\%)$ concentrations. The starting solution was sprayed onto heated substrates at $450^{\circ} \mathrm{C}$ by using an airbrush spray with pressurized air. To keep the substrate temperature constant, the precursor solution was deposited cyclically, $8 \mathrm{~s}$ of spraying followed by $50 \mathrm{~s}$ without spraying. The spray nozzle to substrate distance was adjusted to $35 \mathrm{~cm}$, and to get the uniform film in thickness the lateral speed of the airbrush was set to $1 \mathrm{~cm} / \mathrm{s}$ and the volumetric spray rate was set to approximately $0.3 \mathrm{ml} / \mathrm{s}$ by adjusting the air pressure. It has been shown that the thin films are in hexagonal wurtzite structure and are in accordance with the reference given in the PDF-2:01-079-2205 in previous work of Kerli et al. [4]. The spraying process was repeated 20 times to get the film about $1 \mu \mathrm{m}$ thickness (Fig. 1).

\subsection{XRF measurements}

The boron and fluorine-doped $\mathrm{ZnO}$ thin film samples were irradiated by $59.5 \mathrm{keV}$ photons emitted by $50 \mathrm{mCi}$ ${ }^{241} \mathrm{Am}$ radioactive source. The characteristic X-rays emitted from the target were detected using an UltraLEGe detector (active area is $30 \mathrm{~mm}^{2}$, thickness is $5 \mathrm{~mm}$, and polymer window thickness is $0.4 \mu \mathrm{m}$ ). The measured energy resolution of the detector system is $150 \mathrm{eV}$ at fullwidth half maximum for the $\mathrm{Mn} K_{\alpha}$ line at $5.9 \mathrm{keV}$. The output from the preamplifier, with pulse pileup rejection capability, was fed to a multichannel analyzer interfaced with a computer provided with software for data acquisition and peak analysis. The sample was placed at $45^{\circ}$ angles with respect to the direct beam and fluorescent $\mathrm{X}$-rays emitted $90^{\circ}$ to the detector. All the samples were measured at least three times and in order to minimize the statistical errors, the averages of measurements were

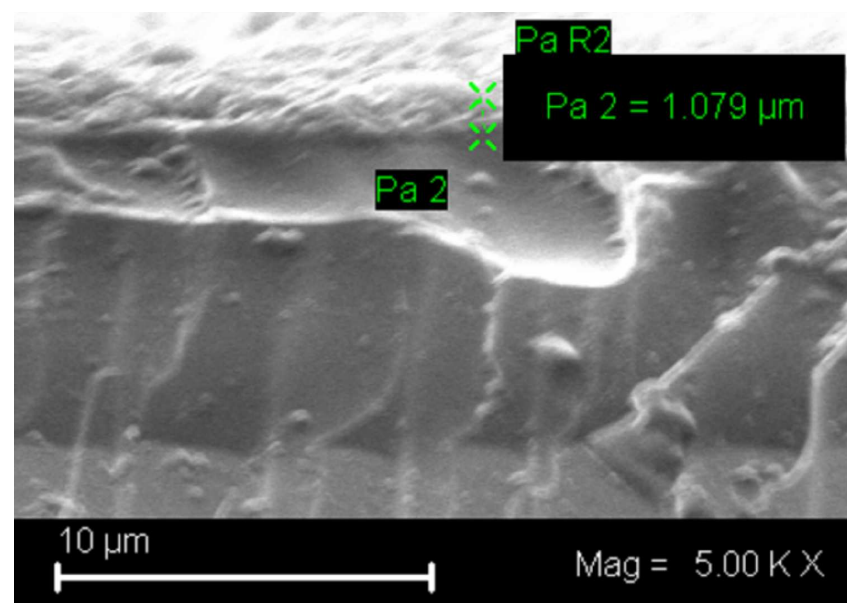

Fig. 1. Cross-section SEM image of a thin film.

taken [3]. $K$ X-ray spectra of zinc in $\mathrm{ZnO}$ thin film doped with $4 \%$ fluorine are shown in Fig. 2 . The $K_{\beta} / K_{\alpha} \mathrm{X}$-ray intensity ratios have been calculated by using the following equation:

$$
\frac{I\left(K_{\beta}\right)}{I\left(K_{\alpha}\right)}=\frac{N\left(K_{\beta}\right)}{N\left(K_{\alpha}\right)} \frac{\varepsilon\left(K_{\beta}\right)}{\varepsilon\left(K_{\alpha}\right)} \frac{\beta\left(K_{\beta}\right)}{\beta\left(K_{\alpha}\right)},
$$

where $N\left(K_{\alpha}\right)$ and $N\left(K_{\beta}\right)$ are counts observed under the peaks corresponding to $K_{\alpha}$ and $K_{\beta}$ X-rays, respectively, and $I_{0} G_{\varepsilon} K_{\alpha}$ and $I_{0} G_{\varepsilon} K_{\beta}$ are the efficiencies of the detector for the $K_{\alpha}$ and $K_{\beta}$ series of X-rays, respectively (since $I_{0} G$ is a constant value for during the experiment, it is not written in Eq. (1) because it is abbreviated in Eq. (1)). $I_{0}$ is the intensity of the incident radiation and $G$ is a geometrical factor. $\beta\left(K_{\alpha}\right)$ and $\beta\left(K_{\beta}\right)$ are the target self-absorption correction factors for both the incident and the emitted radiations. The target self-absorption correction factors and the efficiencies of the detector have been calculated as in the previous paper [18]. $K$ X-ray spectra of $\mathrm{Zn}$ in $\mathrm{ZnO}$ thin film doped $4 \%$ fluorine are given in Fig. 2.

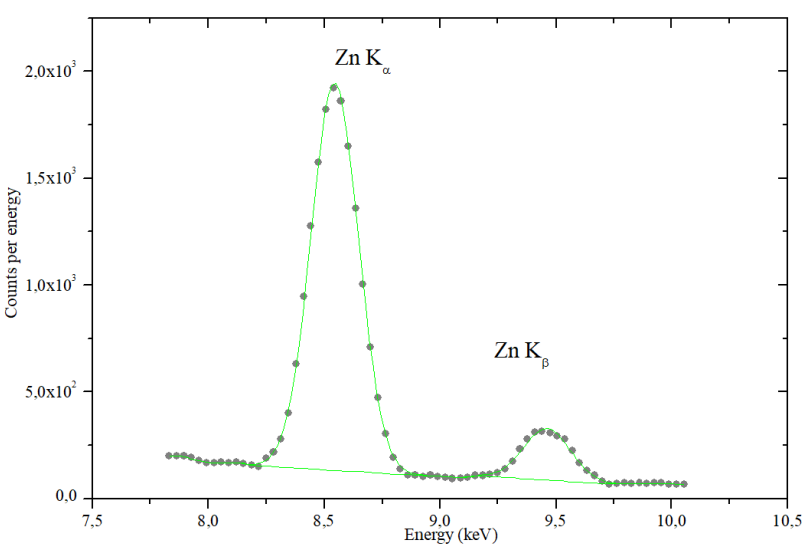

Fig. 2. K X-ray spectra of zinc in $\mathrm{ZnO}$ thin film doped $4 \%$ fluorine. 


\section{Results and discussion}

In this study, the $K_{\beta} / K_{\alpha}$ X-ray intensity ratios of zinc in pure $\mathrm{Zn}, \mathrm{ZnO}$ thin film and fluorine- and borondoped $\mathrm{ZnO}$ thin films have been determined. The present results are given for pure $\mathrm{Zn}$ and $\mathrm{ZnO}$ thin film, and the fluorine- and boron-doped $\mathrm{ZnO}$ thin films in Table I and Table II, respectively. Possible sources of error in the determined the $K_{\beta} / K_{\alpha}$ X-ray intensity ratio are $I G_{\varepsilon}$ determination $(<1-2 \%)$, background determination $(<1 \%)$, self-absorption $(<1-2 \%)$, and counting statistics $(<1 \%)$. The total experimental relative error is estimated to be $4-6 \%$.

$K_{\beta} / K_{\alpha} \mathrm{X}$-ray intensity ratios of pure $\mathrm{Zn}$ and $\mathrm{ZnO}$ thin film.

TABLE I

\begin{tabular}{c|c|c|c|c|c|c|c}
\hline \hline \multicolumn{2}{|c|}{$K_{\beta} / K_{\alpha}$ X-ray intensity ratios } \\
\hline & Present paper & Theor. & \multicolumn{3}{c}{ Experimental } \\
\hline Sample & & $\begin{array}{c}\text { Scofield } \\
{[21]}\end{array}$ & $\begin{array}{c}\text { Ertuğrul } \\
\text { et al. [24] }\end{array}$ & $\begin{array}{c}\text { Khan } \\
\text { et al. [22] }\end{array}$ & $\begin{array}{c}\text { Söğ̈̈t } \\
\text { et al. [25] }\end{array}$ & $\begin{array}{c}\text { Rebohle } \\
\text { et al. [23] }\end{array}$ & $\begin{array}{c}\text { Porikli } \\
\text { et al. [26] }\end{array}$ \\
\hline $\mathrm{Zn}$ & $0.1338 \pm 0.0096$ & 0.1241 & 0.1360 & 0.1320 & 0.1254 & 0.1528 & 0.1359 \\
$\mathrm{ZnO}$ & $0.1148 \pm 0.0068$ & - & - & - & - & 0.1487 & -
\end{tabular}

It is shown from Table I that the experimental values of the $K_{\beta} / K_{\alpha} \mathrm{X}$-ray intensity ratios for pure zinc agree with the theoretical value of Scofield and the other experimental values for pure zinc. On the other hand, the experimental $K_{\beta} / K_{\alpha}$ X-ray intensity ratio value of the undoped $\mathrm{ZnO}$ thin film is much lower than that of the pure zinc. This can be due to influence of oxidation [23]. The present situation is also shown between the $K_{\beta} / K_{\alpha}$ X-ray intensity ratios of the undoped $\mathrm{ZnO}$ thin film and the theoretical value of Scofield. The reason is that Scofield has calculated the intensity ratios for pure Zn elements; so, it does not show the dependence on the formal oxidation number. Besides, the deviations between the present and other experimental values can arise from a different detector type, a different exciting energy, a different detector efficiency and precision in measurements as well as the sample difference.

The experimental $K_{\beta} / K_{\alpha}$ X-ray intensity ratios of $\mathrm{Zn}$ in fluorine- and boron-doped $\mathrm{ZnO}$ thin films and relative $K_{\beta} / K_{\alpha}$ X-ray intensity ratios with respect to undoped $\mathrm{ZnO}$ thin film are given in Table II. The results show that there is a lack of consistency between undoped $\mathrm{ZnO}$ thin film and doped $\mathrm{ZnO}$ thin films. For fluorine concentrations from $1 \%$ to $3 \%$ the $K_{\beta} / K_{\alpha}$ X-ray intensity ratios of $\mathrm{Zn}$ is lower than that of undoped $\mathrm{ZnO}$ thin film, whereas for other two fluorine concentrations the values are higher. However, when the amounts of fluorine doping increase, the intensity ratios increase as shown in Fig. 3. The $K_{\beta} / K_{\alpha} \mathrm{X}$-ray intensity ratios of $\mathrm{Zn}$ for $2 \%$ boron-doped $\mathrm{ZnO}$ thin film is higher than that of undoped $\mathrm{ZnO}$ thin film. For boron doping from $3 \%$ to $5 \%$ the values of the intensity ratios are lower. On the other hand, as the amounts of boron doping increases from $2 \%$ to $5 \%$, the values of intensity ratios decrease as shown in Fig. 3. When boron-doped is $1 \%$ and fluorine-doped are changed by $1 \%$ to $3 \%$, the $K_{\beta}$ to $K_{\alpha}$ X-ray intensity ratios of $\mathrm{Zn}$ in $\mathrm{ZnO}: \mathrm{B}: \mathrm{F}$ are lower than that of undoped $\mathrm{ZnO}$ thin film. If boron-doped is $2 \%$ and fluorine-doped are changed from $1 \%$ to $3 \%$, the $K_{\beta}$ to $K_{\alpha}$ X-ray intensity ratio of $\mathrm{Zn}$ for $1 \%$ fluorine doping is higher than that of undoped $\mathrm{ZnO}$ thin film, for others they are lower.
$K_{\beta} / K_{\alpha}$ X-ray intensity ratios of fluorine- and borondoped $\mathrm{ZnO}$ thin film $\left(\left(I_{K_{\beta}} / I_{K_{\alpha}}\right)_{A}\right.$ experimental $K_{\beta}$-to$K_{\alpha}$ X-ray intensity ratios and $\left(I_{K_{\beta}} / I_{K_{\alpha}}\right)_{B}$ relative $K_{\beta}$ to- $K_{\alpha}$ X-ray intensity ratios with respect to $\mathrm{ZnO}$ thin film)

\begin{tabular}{c|c|c|c|c}
\hline \hline \multicolumn{5}{c}{$K_{\beta} / K_{\alpha}$ X-ray intensity ratios } \\
\hline Sample & $\begin{array}{c}\text { Amount } \\
\text { of doping } \\
F[\%]\end{array}$ & $\begin{array}{c}\text { Amount } \\
\text { of doping } \\
B \text { [\%] }\end{array}$ & $\left(I_{K_{\beta}} / I_{K_{\alpha}}\right)_{A}$ & $\left(I_{K_{\beta}} / I_{K_{\alpha}}\right)_{B}$ \\
\hline $\mathrm{ZnO}$ & - & - & $0.1148 \pm 0.0068$ & 1.0000 \\
$\mathrm{ZnO}: \mathrm{F}$ & 1 & - & $0.1057 \pm 0.0079$ & 0.9207 \\
$\mathrm{ZnO}: \mathrm{F}$ & 2 & - & $0.1084 \pm 0.0048$ & 0.9443 \\
$\mathrm{ZnO}: \mathrm{F}$ & 3 & - & $0.1128 \pm 0.0090$ & 0.9826 \\
$\mathrm{ZnO}: \mathrm{F}$ & 4 & - & $0.1178 \pm 0.0106$ & 1.0261 \\
$\mathrm{ZnO}: \mathrm{F}$ & 5 & - & $0.1195 \pm 0.0117$ & 1.0409 \\
$\mathrm{ZnO}: \mathrm{B}$ & - & 2 & $0.1171 \pm 0.0104$ & 1.0200 \\
$\mathrm{ZnO:B}$ & - & 3 & $0.1072 \pm 0.0084$ & 0.9337 \\
$\mathrm{ZnO}: \mathrm{B}$ & - & 4 & $0.1043 \pm 0.0073$ & 0.9085 \\
$\mathrm{ZnO}: \mathrm{B}$ & - & 5 & $0.1010 \pm 0.0098$ & 0.8798 \\
$\mathrm{ZnO}: \mathrm{B}: \mathrm{F}$ & 1 & 1 & $0.1114 \pm 0.0108$ & 0.9704 \\
$\mathrm{ZnO}: \mathrm{B}: \mathrm{F}$ & 2 & 1 & $0.1106 \pm 0.0087$ & 0.9634 \\
$\mathrm{ZnO} \mathrm{B}: \mathrm{F}$ & 3 & 1 & $0.1091 \pm 0.0071$ & 0.9503 \\
$\mathrm{ZnO}: \mathrm{B}: \mathrm{F}$ & 1 & 2 & $0.1211 \pm 0.0920$ & 1.0549 \\
$\mathrm{ZnO}: \mathrm{B}: \mathrm{F}$ & 2 & 2 & $0.1144 \pm 0.0093$ & 0.9965 \\
$\mathrm{ZnO}: \mathrm{B}: \mathrm{F}$ & 3 & 2 & $0.1110 \pm 0.0101$ & 0.9669 \\
& & & &
\end{tabular}

Besides, as the amounts of fluorine doping increase and the amounts of boron doping are constant, the intensity ratio values decrease as shown from Fig. 4. The inconsistency between the intensity ratios of undoped $\mathrm{ZnO}$ thin film and doped $\mathrm{ZnO}$ thin films can be explained by changing in $3 d$ electron population due to delocalization and/or charge transfer [16]. The crystal structure of the undoped $\mathrm{ZnO}$ thin film has wurtzite hexagonal. Boron and fluorine doping did not change the structure. However, as seen from Table I, the intensity ratios of $\mathrm{ZnO}$ thin films has increased and decreased by the concentrations of $\mathrm{F}$ and $\mathrm{B}$ doping, respectively. This indicates that the fluorine and 


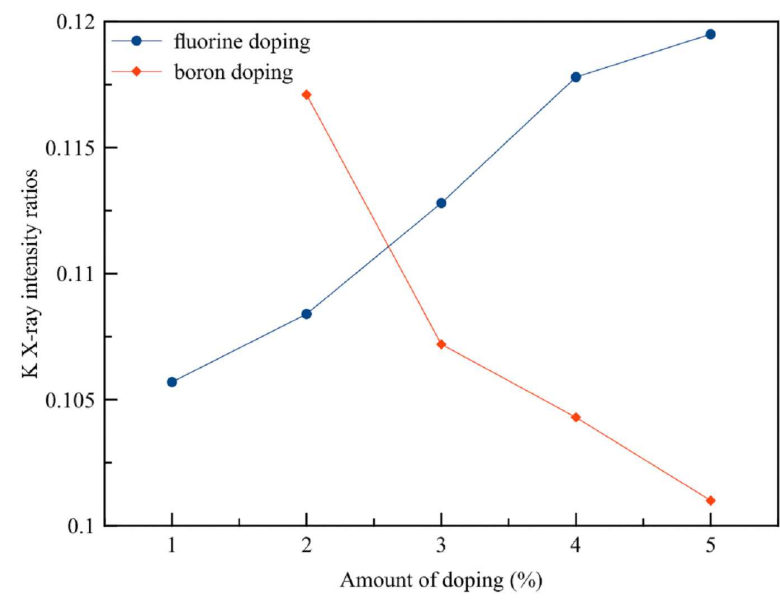

Fig. 3. The change of $K_{\beta} / K_{\alpha}$ X-ray intensity ratios of $\mathrm{Zn}$ according to the amounts of fluorine and boron doping in $\mathrm{ZnO}$ thin films.

boron which enter the structure and replace with oxygen has changed the crystal parameters [4]. Fluorine has a bigger electronegativity value than oxygen, so it attracts more valence electrons than oxygen. Boron has a smaller electronegativity value than oxygen and a smaller from that of zinc, so it attracts less electron than oxygen. This causes the valence electronic structure of zinc to change, thus resulting in changes in the $K_{\beta} / K_{\alpha}$ X-ray intensity ratios of $\mathrm{Zn}$ in fluorine- and boron-doped $\mathrm{ZnO}$ thin films.

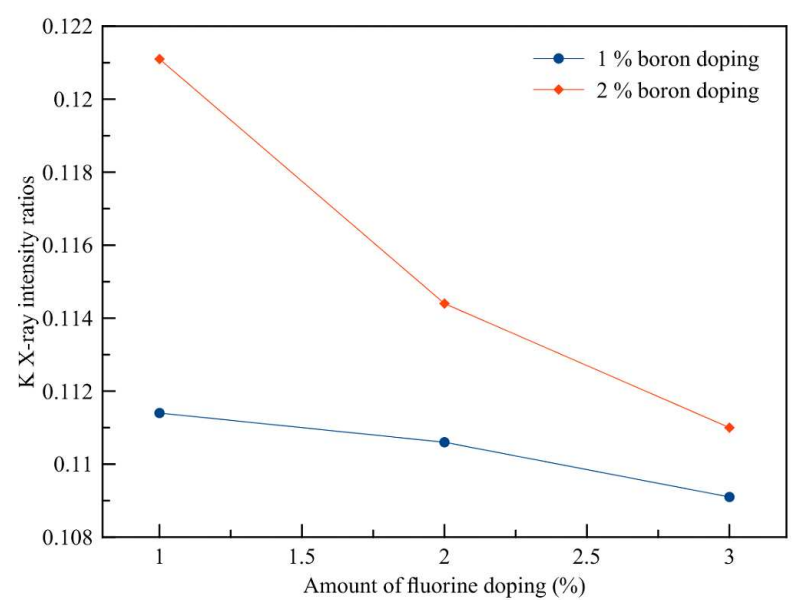

Fig. 4. The change of $K_{\beta} / K_{\alpha} \mathrm{X}$-ray intensity ratios of $\mathrm{Zn}$ according to the amounts of fluoride doping in $\mathrm{ZnO}$ thin films (amount of boron doping was fixed at 1 and $2 \%)$.

\section{Conclusion}

In this study, the $K_{\beta} / K_{\alpha} \mathrm{X}$-ray intensity ratios of zinc in pure $\mathrm{Zn}$, undoped $\mathrm{ZnO}$ thin film and fluorine- and boron-doped $\mathrm{ZnO}$ thin films have been determined. The experimental values of the intensity ratios of pure zinc agree with the theoretical value and the other experimental values. The lack of consistency between the experimental values of pure zinc and the undoped $\mathrm{ZnO}$ thin film can arise from the influence of oxidation. Besides, the reason in the deviations between the intensity ratios of the undoped and doped thin films can be from change in the valence electronic configuration due to delocalization and/or charge transfer.

\section{Acknowledgments}

This work was supported by Scientific Research Fund of Kahramanmaras Sutcu Imam University, Turkey (project No. 2012/4-3 YLS), and all the authors are thankful for this support.

\section{References}

[1] T. Wagner, Thin Film Science Max-Planck Institut für Metallforschung, Stuttgart 1999.

[2] I.H. Karahan, K. Karabulut, U. Alver, Phys. Scr. 79, 055801 (2009).

[3] Ö. Söğüt, C. Donuk, G. Apaydın, O.F. Bakkaloğlu, Can. J. Phys. 92, 435 (2014).

[4] S. Kerli, U. Alver, A. Tanrıverdi, B. Avar, Protect. Met. Phys. Chem. Surf. 50, 797 (2014).

[5] S. Zhao, Y. Zhou, Y. Liu, K. Zhao, S. Wang, W. Xiang, Z. Liu, P. Han, Z. Zhang, Z. Chen, H. Lu, K. Jin, B. Cheng, G. Yang, Appl. Surf. Sci. 253, 726 (2006).

[6] S. Mondal, K.P. Kanta, P. Mitra, J. Phys. Sci. 12, 221 (2008).

[7] C.Y. Tsay, K.S. Fan, Mater. Trans. 49, 1900 (2008).

[8] S. Benramache, B. Benhaoua, Superlatt. Microstruct. 52, 807 (2012).

[9] S. Sönmezoğlu, E. Akman, Appl. Surf. Sci. 318, 319 (2014).

[10] J.R. Duclère, M. Novotny, A. Meaney, R. O'Haire, E. McGlynn, M.O. Henry, P.J. Mosnier, Superlatt. Microstruct. 38, 397 (2005).

[11] T. Yamada, T. Nebiki, S. Kishimoto, H. Makino, K. Awai, T. Narusawa, T. Yamamoto, Superlatt. Microstruct. 42, 68 (2007).

[12] S. Abed, M.S. Aida, K. Bouchouit, A. Arbaoui, K. Iliopoulos, B. Sahraoui, Opt. Mater. 33, 968 (2011).

[13] S. Benramache, B. Benhaoua, F. Chabane, J. Semicond. 33, 093001 (2012).

[14] C.R. Bhuinya, H.C. Padhi, J. Phys. B At. Mol. Opt. Phys. 25, 5283 (1992).

[15] Ö. Söğüt, E. Buyukkasap, A. Kucukonder, M. Ertuğrul, Ö. Şimşek, Appl. Spectrosc. Rev. 30, 175 (1995).

[16] S. Raj, H.C. Padhi, M. Polasik, F. Pawlowski, D.K. Basa, Solid State Commun. 116, 563 (2000).

[17] F. Pawlowski, M. Polasik, S. Raj, H.C. Padhi, D.K. Basa, Nucl. Instrum. Methods Phys. Res. B 195, 367 (2002).

[18] Ö. Söğüt, Radiochim. Acta 97, 695 (2009). 
[19] M. Dogan, E. Tirasoglu, I.H. Karahan, N.K. Aylıkcı, V. Aylıkcı, A. Kahoul, H.A. Cetinkara, O. Serifoglu, Radiat. Phys. Chem. 87, 6 (2013).

[20] E. Cengiz, O.M. Özkendir, M. Kaya, E. Tirasoglu, I.H. Karahan, S. Kimura, T. Hajiri, J. Electron. Spectrosc. Relat. Phenom. 192, 55 (2014).

[21] J.H. Scofield, At. Data Nucl. Data Tables 14, 94550 (1974).
[22] M.R. Khan, M. Karimi, X-ray Spectrom. 9, 33 (1980).

[23] L. Rebohle, U. Lehnert, G. Zschornack, X-ray Spectrom. 25, 295 (1996).

[24] M. Ertuğrul, Ö. Söğüt, Ö. Şimşek, E. Büyükkasap, J. Phys. B At. Mol. Opt. Phys. 34, 909 (2001).

[25] Ö. Söğüt, E. Büyükkasap, H. Erdoğan, Radiat. Phys. Chem. 64, 343 (2002).

[26] S. Porikli, Y. Kurucu, Instrument. Sci. Technol. 36, 341 (2008). 